\title{
Pulparegeneration und die zukünftigen Herausforderungen
}

\author{
Traditionell wird infiziertes oder nekrotisches Pulpagewebe entfernt und anschließend mit anor- \\ ganischem Material wie Guttapercha per Wurzelkanalbehandlung ersetzt. Mit dem Verlust der \\ Pulpa, die die Odontoblasten ernährt, steigt jedoch das Risiko einer Zahnfraktur. Wünschenswert \\ ist daher die Wiederherstellung der Pulpa mit Hilfe von regenerativen Verfahren.
}

Klassischerweise sind zur Regeneration drei Faktoren notwendig: Zellen, Wachstumsfaktoren und eine entsprechende Matrix, in welche die Zellen einwachsen können. In vitro ist die Regeneration von Pulpagewebe bereits vielen Arbeitsgruppen gelungen. In klinischen Studien wird bei nicht ausgewachsenen Zähnen die Revaskularisation der Pulpa durch das so genannte Homing versucht. Zu Beginn der Pulparegeneration füllt man den aufbereiteten Zahn mit Blut und desinfizierenden Antibiotika. Im Ergebnis bildet sich aber kein Pulpagewebe, sondern ein gering durchblutetes Narbengewebe. Die Erfolgsrate einer Revaskularisation ist gering.

\section{Funktionelle Pulparegeneration gewünscht}

Neben einer Revaskularisation sind für eine funktionelle Pulparegeneration jedoch auch eine Reinnervation und die Fähigkeit einer Dentinproduktion notwendig. Grundsätzliche Voraussetzung zur Regeneration eines pulpaähnlichen Gewebes sind die gründliche Reinigung des Wurzelkanals im Rahmen der Wurzelkanalaufbereitung und die Erweiterung des apikalen Foramens. Darauffolgend Stammzellen in den Wurzelkanal zu bringen oder zu locken, wird als Zell-Homing bezeichnet. Neben der mechanischen Reinigung und Gabe von Antibiotika desinfizieren Spültechniken mit Hilfe von apikalem, negativem Druck oder Ultraschall. Desweiteren kommt der Laser zur Desinfektion des Wurzelkanals zum Einsatz. Die traditionelle Spülung mit zehn Millilitern 1,25-prozentigem Natriumhypochlorit soll nämlich nur 90 Prozent der Bakterien des Wurzelkanals beseitigen kön-

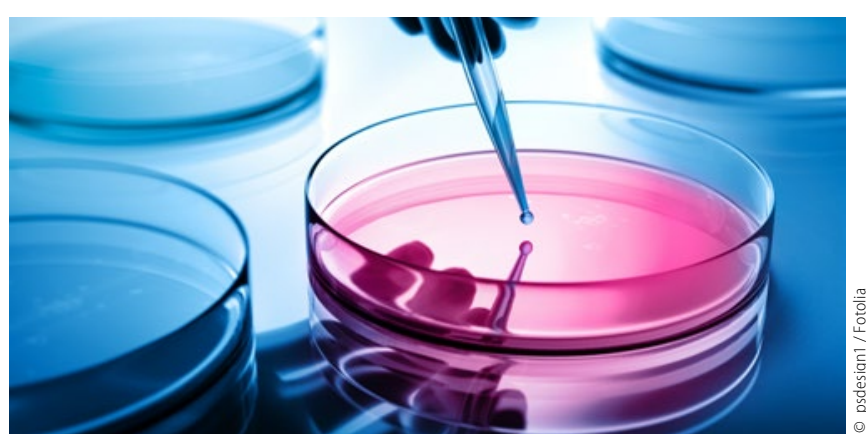

nen. In klinischen Studien wird die Anwendung einer Dreifachkombination von Antibiotika empfohlen (Metronidazol, Ciprofloxacin, Minocyclin). Entgegen der Regel, das apikale Foramen mindestens einen Millimeter zu öffnen, konnten Zähne auch bei einer apikalen Öffnung von nur 0,32 Millimetern ihre Pulpa regenerieren.

Bei noch nicht ausgewachsenen Zähnen sollte auf eine mechanische Reinigung der Zähne verzichtet werden, damit noch im Wurzelkanal verbliebene, vitale Pulpastammzellen die Pulpa regenerieren können. Neben den Pulpastammzellen wurden auch Stammzellen aus dem apikalen Papillengewebe und dem Knochenmark zur Regeneration angewandt, die durch autokrine Sekretion von Wachstumsfaktoren zum sogenannten Homing-Effekt beitragen.

\section{Signalproteine locken Stammzellen}

Signalproteine und Wachstumsfaktoren wie der SDF-1 $\alpha$ („stromal cell-derivated factor“), bFGF („fibroblast growth factor“), PDGF („platelet-derived growth factor“), der SCF („stem cell factor") und der G-CSF ("granulocyte colony-stimulating factor") helfen, diese mesenchymalen Stammzellen anzuziehen.

Das Augenmerk der Forschung liegt auf der Gewinnung von Pulpastammzellen aus dem jeweiligen Wurzelkanal. Dafür muss auf eine schonende wie auch effektive Reinigung der Kanäle geachtet werden. Stammzellen mit vaskulogenem und zementogenem Potenzial müssen durch Signalproteine angelockt werden, die in den Wurzelkanal eingebracht und freigesetzt wurden.

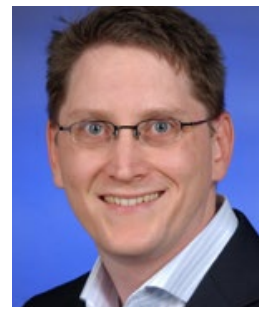

Prof. Dr. Dr. Felix P. Koch

Autor des Wissenschaftlichen Infodienstes, Lehrbeauftragter der Uniklinik Frankfurt, Praxisklinik für Mund-, Kiefer- und plastische Gesichtschirurgie in Wiesbaden. Mail:wid@fvdz.de 